\title{
Electrothermally Actuated RF MEMS Switches Suspended on a Low-Resistivity Substrate
}

\author{
David Girbau, Lluís Pradell, Member, IEEE, Antonio Lázaro, and Àlvar Nebot
}

\begin{abstract}
This paper presents an electrothermally actuated lateral resistive-contact switch for application to low-gigahertz-band communication systems. It was manufactured on a standard low-resistivity substrate, and its RF performance was improved by suspending the structures $25 \mu \mathrm{m}$ from the substrate, which is a strategy for future integration with active devices in the system-on-chip concept. Measured insertion losses are $-0.26 \mathrm{~dB}$ at $1 \mathrm{GHz}$ and $-0.65 \mathrm{~dB}$ at $6 \mathrm{GHz}$, return losses are $-29 \mathrm{~dB}$ at $1 \mathrm{GHz}$ and $-25 \mathrm{~dB}$ at $6 \mathrm{GHz}$, and isolations are $-52 \mathrm{~dB}$ at $1 \mathrm{GHz}$ and $-26 \mathrm{~dB}$ at $6 \mathrm{GHz}$. The device is driven by a metal electrothermal actuator, which achieves large displacements and contact forces at much lower temperatures than traditional polysilicon electrothermal actuators. The RF power handling characteristics are also addressed and measured.

[2007-0051]
\end{abstract}

Index Terms-Electrothermal actuator, low-resistivity substrate, microelectromechanical systems (MEMS) switch, system on chip.

\section{INTRODUCTION}

$\mathbf{T}$ HE TREND of communication systems toward miniaturization and integration is limited by bulky off-chip passive elements, such as varactors, p-i-n diodes, inductors, quartz crystals, and surface acoustic wave filters, which cannot be integrated with active circuitry while maintaining high performance [1]. In consequence, RF microelectromechanical systems (MEMS) is considered to be a future enabling technology that can replace off-chip passives and ensure high-performance, linear [2], integrated, and reconfigurable devices.

The integration of MEMS switches into RF subsystems is expected to provide benefits. Capacitive series and shunt switches (based on a metal-dielectric-metal contact) have been implemented in a number of applications, mainly at frequencies above $10-15 \mathrm{GHz}$ [3] and also at frequencies as low as $7 \mathrm{GHz}$, using inductively tuned capacitive switches [4]. Resistivecontact (or dc-contact) switches, based on a metal-metal

Manuscript received February 28, 2007; revised May 22, 2007. This work was supported by the Spanish Government Project ESP2004-07067-C03-03, Ministerio de Ciencia y Tecnología (MCYT). Subject Editor M. Mehregany.

D. Girbau is with the Department of Signal Theory and Communications, Universitat Politècnica de Catalunya, 08034 Barcelona, Spain, and also with the Universitat Autònoma de Barcelona, 08193 Bellatera, Spain (e-mail: DGirbauSala@tsc.upc.edu).

L. Pradell and À. Nebot are with the Department of Signal Theory and Communications, Universitat Politècnica de Catalunya, 08034 Barcelona, Spain (e-mail: pradell@tsc.upc.edu).

A. Lázaro is with the Electronics, Electrical and Automatics Engineering Department, University Rovira i Virgili, 43007 Tarragona, Spain (e-mail: antonioramon.lazaro@urv.net).

Color versions of one or more of the figures in this paper are available online at http://ieeexplore.ieee.org.

Digital Object Identifier 10.1109/JMEMS.2007.904744 contact, operate from dc to several tens of gigahertz, perfectly covering the ground wireless communication bands, i.e., global system for mobile communication, Universal Mobile Telecommunications System, industrial, scientific, and medical (ISM) bands, high-speed wireless local area network, or cable television, which are under $6 \mathrm{GHz}$. Most resistive-contact switches - mainly those based on electrostatic actuation-have been implemented using out-of-plane motion, which is perpendicular to the substrate [5]. However, a small number of in-plane RF devices (lateral movement, parallel to the substrate) have also been presented thus far, most of which are electrothermally-actuated [6]. Also some electrostaticallyactuated lateral switches have been presented [7], [8]; in this topology, the most important limitation is the need for high aspect ratio structures (thick elements with small gaps) that are capable of producing electrostatic forces that are strong enough to ensure good switch contact with moderate actuation voltage.

On the other hand, the use of low-resistivity substrates is common in many microelectronic integrated circuit processes. Therefore, in order to integrate RF MEMS switches with active circuitry on the same chip fabricated in a single process (system on chip), strategies to reduce losses in RF MEMS manufactured in low-resistivity substrates are essential. If other dedicated processes in the manufacture of RF MEMS (based on high-resistivity silicon, glass or ceramic substrates) were considered, integration had to be made at package level (system in a package).

This paper presents an in-plane resistive-contact series MEMS switch based on electrothermal actuation, for operation in low-gigahertz band. The main characteristic of this device is its manufacture on a low-resistivity substrate $(1-2 \Omega \cdot \mathrm{cm})$. In order to reduce substrate loss, a trench $25-\mu \mathrm{m}$ deep is carved under the device, thus creating a suspended switch. This demonstrates that a good RF performance can be obtaineddespite the use of low-resistivity substrates - by suspending the elements a few micrometers apart. The results measured are comparable to those obtained with high-resistivity substrates and dedicated processes [6], [7]. The second contribution of this paper is the use of metal electrothermal actuators in RF applications. Electrothermal actuators develop high forces [9] with a direct impact on optimum resistive contacts [10]. It is shown that the use of nickel as actuator building material permits large displacements with low temperatures (important in terms of packaging), in contrast to the traditional polysilicon electrothermal actuators used in other works [6], [11]. Furthermore, the lateral topology and the use of nickel result in a potential for cofabrication, i.e., implementation of the RF lines, contact, and actuator in the same lithographic step [7]. 
On the other hand, the issue of RF power handling is of major concern in current RF MEMS research [12] in order to integrate RF MEMS in transmitters, as, for instance, in reconfigurable solid-state power amplifiers. This subject is addressed in some works in literature for the case of electrostatic actuation, mainly in capacitive shunt devices, where the limitations are derived from the effects of self-switching, RF latching, and dielectric charging [13]-[16]. The structure proposed in this paper provides complete independence between the actuation and the RF signal. In consequence, the power-handling limitation is in the contact itself, due to current and temperature. The effects of RF power on the device are addressed and characterized.

The device was manufactured using MetalMumps technology [17], which is a recent commercially available multiproject wafer process. To date, few works dealing with RF devices based on this technology have been presented. The work in [18] reports a variable capacitor with two movable plates, while in [19], theoretical approximations to MetalMumps-based devices are provided. A previous authors' work [8] proposes using MetalMumps to implement lateral resistive-contact electrostatically actuated RF MEMS switches.

This paper is organized as follows. Section II presents the switch design, a brief review of the technology and the main device characteristics, and the switch components: metallic electrothermal actuator, RF access pads, resistive contact, and suspended RF lines. Section III presents the switch characterization and the concept validation and is divided into two parts: actuator characterization and small-signal simulation and measurement. Section IV discusses the device RF power handling and measurement, and Section $\mathrm{V}$ provides the conclusions.

\section{Switch Design}

Fig. 1 shows a cross-sectional 3-D view and photograph of the designed switch, outlining its main building parts: signal lines, RF pads, switch contact, actuator, bias access, and mechanical supports. These elements are further analyzed in the following sections.

The switch is based on a coplanar-strip (CPS) transmission line and a series configuration with two resistive gold-gold contacts. Switching between the two states is done by means of an electrothermal buckle-beam actuator, which produces high forces and rectilinear motion [11], [20], [21]. When no current is injected into the actuator, the switch is in its OFF state, and when a current is injected, it changes to its ON state. The device is completely suspended $25 \mu \mathrm{m}$ over the substrate, anchored only at the access pads [see Fig. 1(a) and Section II-D].

The manufacturing process [17] (see Fig. 1) includes a $2-\mu \mathrm{m}$-thick isolation oxide layer on top of the low-resistivity (1-2 $\Omega \cdot \mathrm{cm}) 675-\mu \mathrm{m}$-thick silicon $\left(\varepsilon_{\mathrm{r}}=11.8\right)$ substrate [see Fig. 1(a)]. A sacrificial oxide layer (oxide1) is used in defining the area in which the trench under the device will be patterned (to suspend the structures) at the end of the process. Two sequential silicon-nitride layers (nitride1 + nitride2, $0.35+$ $0.35-\mu \mathrm{m}$ thick) provide extra isolation of the unsuspended device areas (anchors of suspended lines) from the substrate, as well as electrical and thermal isolations between actuator and contact (see Section II-C). The access pads are also used

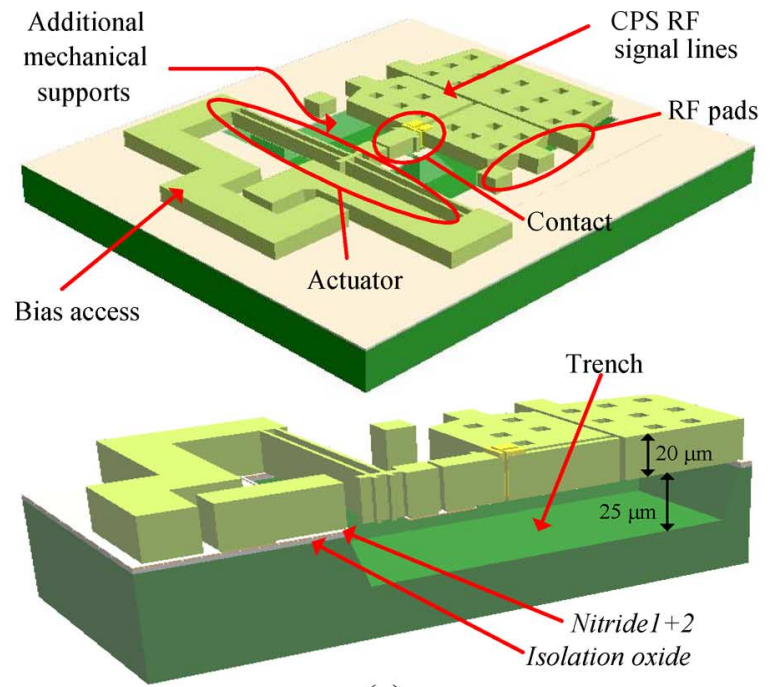

(a)

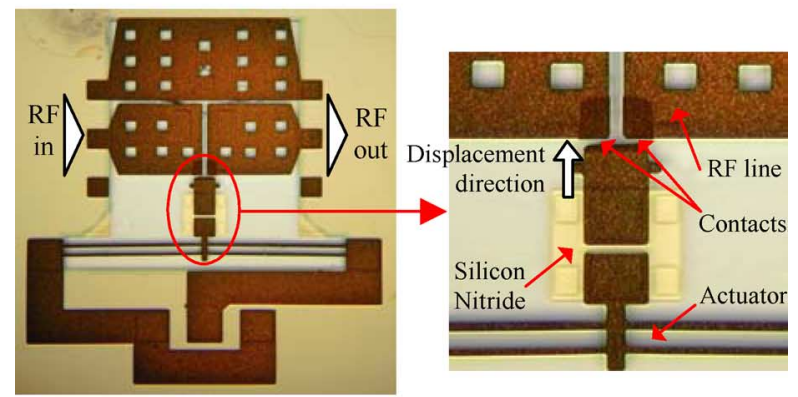

(b)

Fig. 1. (a) Cross-sectional 3-D view and (b) photograph of a series switch manufactured with MetalMumps and the details of the contact.

as anchors for the whole suspended structure. These anchors are defined in a second sacrificial oxide layer (oxide2). After electroplating the structural nickel layer (20- $\mu \mathrm{m}$ thick), a sidewall gold layer is electroplated in areas where mechanical contacts occur. After releasing the structures by etching the two oxide layers (oxide1 and oxide2) using a 49\% hydrofluoric acid solution, a $25-\mu \mathrm{m}$ trench is opened underneath using potassium hydroxide. This trench is an essential feature in order to reduce the loss produced by the low-resistivity substrate, since the CPS electromagnetic field distribution is expected to be confined to (and close to) the CPS gap, and its penetration into the substrate is minor.

\section{A. Metallic Electrothermal Actuators Versus Polysilicon Actuators}

An electrothermal actuator generates movement through an expansion of its materials caused by the Joule effect. The analysis developed here, based on the authors' actuator model provided in [11], shows that metallic electrothermal actuators might offer advantages over actuators made of materials with higher resistivity $(\rho)$, such as polysilicon. Reference [22] defines a figure of merit $Q=\alpha / k E$ for the selection of the actuator building material, where $\alpha$ is the thermal expansion coefficient, $k$ is the thermal conductivity, and $E$ is the Young modulus. Table I compares the nominal values of polysilicon and nickel properties. 
TABLE I

Properties of Polysilicon AND Nickel/Figure of MERIT

\begin{tabular}{|c|c|c|c|c|c|}
\hline & $\alpha(\mathrm{ppm} / \mathrm{K})$ & $\rho(\Omega-\mathrm{m})$ & $k(\mathrm{~W} / \mathrm{mK})$ & $E(\mathrm{Gpa})$ & $Q$ \\
\hline Polysilicon & 2.5 & $3.1 \times 10^{-5}$ & 65 & 165 & $2.33 \times 10^{-13}$ \\
\hline Nickel & 12 & $8 \times 10^{-8}$ & 91 & 210 & $6.28 \times 10^{-13}$ \\
\hline \hline
\end{tabular}

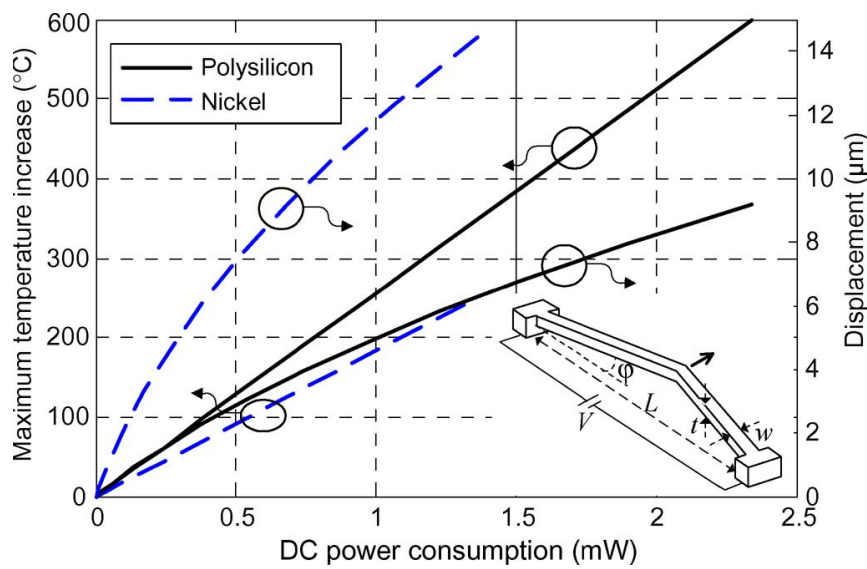

Fig. 2. Maximum temperature increase and displacement of the nickel and polysilicon actuators as a function of the applied dc power. Small plot: bucklebeam actuator 3-D view and main parameters.

The $Q$-factor obtained with nickel is higher than that obtained with polysilicon, essentially due to the fact that the nickel thermal expansion coefficient is approximately five times greater than that of polysilicon. This means that the same displacements can be obtained at a much lower temperature, a characteristic which could make metallic actuators preferable to polysilicon actuators as candidates for packaged devices. On the other hand, creep and high-cycle fatigue of nickel structures, particularly at elevated temperatures, might limit the use of metallic electrothermal actuators [23], [24] in some applications due to the impact on their reliability and lifetime. However, in [25], bidirectional nickel electrothermal electromagnetic actuators (also fabricated with MetalMumps) are applied to low-frequency microrelays, reporting tested results over 1 million cycles without failure.

A buckle-beam actuator topology has been used in this paper. Polysilicon buckle beams are well-known structures [11], [20] (see small inset in Fig. 2). Analysis of the efficiency improvement using nickel, instead of polysilicon, was performed in a buckle-beam actuator with the dimensions $L=600 \mu \mathrm{m}, w=$ $3 \mu \mathrm{m}, t=1.5 \mu \mathrm{m}$, and $\varphi=1^{\circ}$, where $L, w, t$, and $\varphi$ are the actuator length, width, thickness, and prebending angle, respectively. The material properties given in Table I were used.

Fig. 2 shows the maximum increase in temperature and displacement as a function of the applied dc power for the nickel and polysilicon actuators. Larger displacements can be observed in the nickel actuator with much lower maximum temperatures and greatly reduced dc power consumption. Table II compares the two actuators. In the first column, the dc power consumption is fixed to the value at which the nickel actuator reaches its maximum permitted temperature $(P=1.362 \mathrm{~mW}$, $T=250{ }^{\circ} \mathrm{C}$ ). It is observed that much larger displacements $(\Delta x)$ can be achieved with nickel. Furthermore, if the polysilicon actuator is driven close to its limit $(P=2.34 \mathrm{~mW}$ and $T=600{ }^{\circ} \mathrm{C}$ ), displacements are still much smaller than those
TABLE II

COMPARISON BETWEEN NICKEL AND POLYSILICON BUCKLE-BEAM ACTUATORS

\begin{tabular}{|c|c|c|}
\hline Applied DC power & $P=1.362 \mathrm{~mW}$ & $P=2.34 \mathrm{~mW}$ \\
\hline Polysilicon & $\begin{array}{l}I=0.573 \mathrm{~mA} \\
V=2.369 \mathrm{~V} \\
\Delta T=352^{\circ} \mathrm{C} \\
\Delta x=6.25 \mu \mathrm{m}\end{array}$ & $\begin{array}{l}I=0.752 \mathrm{~mA} \\
V=3.11 \mathrm{~V} \\
\Delta T=600^{\circ} \mathrm{C} \\
\Delta x=9.17 \mu \mathrm{m}\end{array}$ \\
\hline Nickel & $\begin{array}{l}I=11.3 \mathrm{~mA} \\
V=120.5 \mathrm{mV} \\
\Delta T=250^{\circ} \mathrm{C} \\
\Delta x=14.44 \mu \mathrm{m}\end{array}$ & \\
\hline
\end{tabular}

obtained with the nickel actuator at $1.362 \mathrm{~mW}$. Values of voltage $(V)$ and current $(I)$ are also given.

One advantage of using MetalMumps in designing electrothermal actuators is the availability of nickel as a structural layer. On the other hand, the actual dimensions and design rules of MetalMumps (specifically, a nickel thickness of $20 \mu \mathrm{m}$ and a minimum allowed width of $8 \mu \mathrm{m}$ ) prevent the designer from creating low-consumption actuators. Despite this limitation, it is still possible to demonstrate the feasibility of applying these actuators to RF devices, since current consumption can be scaled easily with actuator dimensions.

It must also be noted that when using metallic electrothermal actuators, the access bias lines must be carefully designed, since their power consumption might be comparable to that of the actuator. Therefore, the bias access width in this paper was designed to be large enough (see Fig. 1) to ensure that the total power consumption of bias access lines amounts to less than $20 \%$ of the actuator power consumption.

\section{B. RF Access Pads}

Access pads provide interface with the exterior. The actual effects of the access pads on device performance depend mainly on the substrate characteristics. When using a low-resistivity substrate with a narrow dielectric layer on top, as is the case in MetalMumps, the main limiting parameter in RF devices is the signal capacitive coupling to the substrate. The pads are designed here to be connected to a coplanar waveguide (CPW) wafer-probe station with a pitch of $150 \mu \mathrm{m}$. There are no available studies of pad topologies using MetalMumps. Consequently, a large number of RF pad topologies were assessed in order to find those that best satisfy low parasitic capacity and good mechanical stability requirements. Two of them are proposed here: a "conventional" structure, which is shown in Fig. 3(a), and a new (micromachined) pad, with a partial trench underneath, of which the vertical cross section is shown in Fig. 3(b). Fig. 3(c) shows a comparison between the equivalent signal-to-ground parasitic capacity (understood as the capacity of the whole access) measured with the two configurations.

\section{Resistive Contacts}

Insertion loss in series dc-contact switches depends on the quality of the resistive contact. The performance of this contact is itself influenced by the combination of a number of factors 


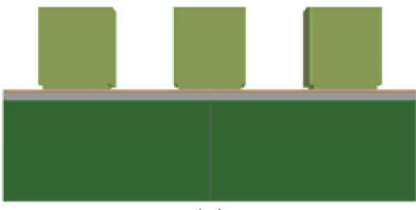

(a) (b)
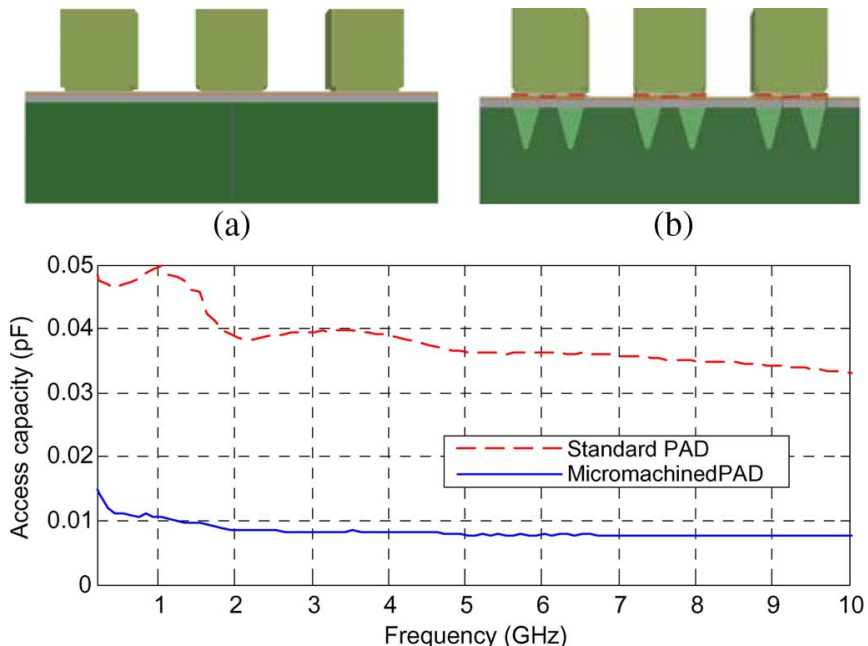

(c)

Fig. 3. Vertical cross sections of two pad topologies implemented with MetalMumps. (a) Standard. (b) Micromachined. (c) Parasitic capacity measurement.

such as material properties (electrical resistivity, roughness, hardness, plasticity, and melting point) [10], real contact area [26] (since the contact occurs only at a number of points scattered across the rough surfaces), contact force [10], adherence force (the force that must be overcome in order to separate the surfaces once contact has occurred), temperature due to current flow through the contact, and manufacturing process [27]. Resistive-contact failure strongly depends on the material selected; it is independent of the actuation principle and is caused by a number of mechanisms such as pitting, hardening, and necking, mainly derived from thermal issues. However, understanding of the failure mechanisms of dccontact switches at medium/high power levels is still poor [28]. Two switching modes are defined: the hot and cold switching (which mean switching with and without the presence of RF power, respectively). In low-RF power conditions, no difference between cold and hot switching is observed, on the contrary to medium- to high-power conditions, where their impact on the switch performance and reliability is different [28]. There are a number of studies in literature devoted to the exploration of microscale contact physics, which also provide models for the different phenomena associated with resistive contacts [10], [26]-[29]. In this paper, issues related to contact failure mechanisms were not investigated, although, as described in the following paragraph, care was taken in designing a contact that would be as robust as possible (given the manufacturing process restrictions) and with good RF and power-handling performance.

Gold was used as the contact material for the designed devices. It is a soft material but it has a high melting point [10] (sintering occurs at approximately $100{ }^{\circ} \mathrm{C}$ [26]) — two properties which make it suitable for use in contacts with reduced heating for high-current applications. Furthermore, gold is corrosion resistant and has excellent electrical and thermal conductivities. Contact surface morphology depends on the manufacturing process (electroplating in MetalMumps), an issue that cannot be controlled by the design. The use of

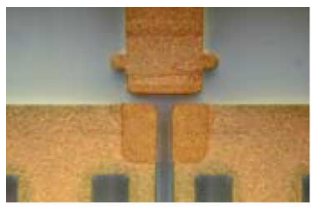

(a)

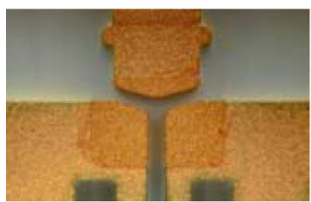

(b)

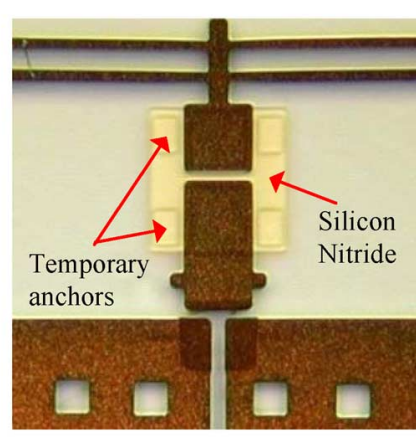

(c)
Fig. 4. (a), (b) Photographs of the square and the triangular manufactured gold contacts. (c) Photograph of the silicon-nitride element for thermal and electrical isolation.

electrothermal actuation is expected to provide a high-force contact, with high restoring force (no adherence problems should be experienced). The limiting factor on RF power for the designed switches is expected to be derived from thermal issues in the real contact area, which is, in turn, mainly determined by material roughness. In [25], a low-frequency microrelay that is manufactured with MetalMumps is presented; the assessment is that gold is a very rough material, thus a postprocessing step is suggested, based on coating the contacts with liquid metal (gallium alloy) to reduce contact resistance to $0.1 \Omega$.

Fig. 4(a) and (b) show photographs of the two designed contact topologies: squared and triangular (guiding structure). Identical results were obtained in both cases. The distance between the RF lines and the mobile element is $7 \mu \mathrm{m}$, which determines the actuator minimum displacement capability. In addition, since the contact area is small, no significant electrostatic force between fixed and mobile parts is expected, making the actuation completely independent on the RF power. Critical points are the electrical and thermal isolations between the actuator and the mobile contact part. Electrical isolation is important in order to prevent actuator loading in the RF line whenever resistive contact occurs. In turn, thermal isolation prevents temperature redistribution when the contact occurs. As shown in Fig. 4(c), a silicon-nitride (nitride1 + 2) structure is placed between the actuator and the mobile part of the contact for isolation purposes, along with temporary anchors to prevent structure cracking during the release process due to stress imbalance, as noted in [17].

\section{Suspended CPS Transmission Lines}

Since the actuator is placed sideways (see Fig. 1), a CPS [30]-[32] transmission-line structure was chosen (see Fig. 5). The access pads (see Section II-B) constitute the main mechanical support for the RF lines, suspended $25 \mu \mathrm{m}$ over the low-resistivity substrate (the separation is defined by the trench [17]). A number of holes in the RF lines are necessary to properly etch the trench underneath.

The following dimensions of the RF lines were obtained from Advanced Design System (ADS)-Momentum simulations for a $50-\Omega$ characteristic impedance: $w_{\text {line }}=220 \mu \mathrm{m}$ (signal 


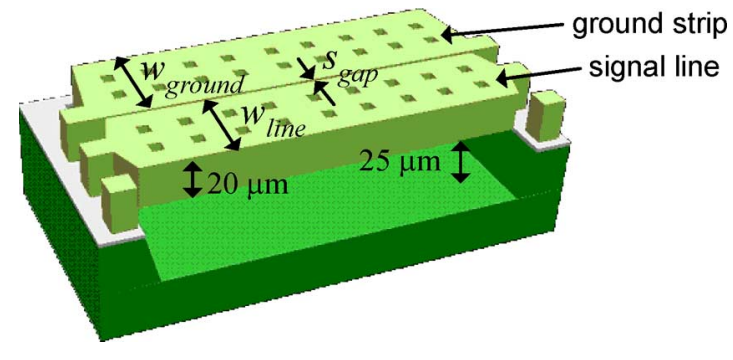

Fig. 5. Transmission-line configuration.

TABLE III

Measured Gap. Current Consumption. Contact Quality

\begin{tabular}{ccc}
\hline \hline \multicolumn{2}{l}{ Measured contact gap } & $7 \mu \mathrm{m}$ \\
\hline \hline \multicolumn{2}{c}{ Current consumption } & Contact quality \\
\hline Array: 2 buckle-beams & 1 buckle-beam & \\
\hline $360 \mathrm{~mA}$ & $180 \mathrm{~mA}$ & Very unstable contact \\
$370 \mathrm{~mA}$ & $185 \mathrm{~mA}$ & Lossy contact \\
$380 \mathrm{~mA}$ & $190 \mathrm{~mA}$ & Good contact \\
\hline \hline
\end{tabular}

linewidth), $w_{\text {ground }}=250 \mu \mathrm{m}$ (ground strip width), and $s_{\text {gap }}=$ $10 \mu \mathrm{m}$ (CPS gap).

\section{SWITCh VALIDATION AND ChaRACTERIZATION}

\section{A. Actuator Characterization}

The actuator that drives the switch is an array of two buckle beams, the main dimensions of which are the following: $L=$ $800 \mu \mathrm{m}, w=8 \mu \mathrm{m}, t=20 \mu \mathrm{m}$, and $\varphi=1.07^{\circ}$. The actuation characteristics are given in Table III.

The measured voltage at the actuator as a function of applied current is not linear (linear behavior could be expected if nickel properties were temperature-independent), as shown in Fig. 6(a). From this result, it is clear that in order to properly predict nickel electrothermal actuator displacement, the nominal nickel properties given in Table I must be fitted according to their temperature dependence. A linear dependence of the nickel resistivity on the temperature is considered [22]. Consequently, the dependence of the voltage $(V)$ on the applied current $(I)$ is $V=I \rho_{0}(1+\xi T) L / w t$, where $\rho_{0}$ is the resistivity at $273 \mathrm{~K}, \xi$ is the resistivity temperature coefficient, and $T$ is the temperature. In the literature, $\xi=3.2 \times 10^{-3}$ has been used [22], but this does not fit the measured and simulated $V-I$ curves in our MetalMumps nickel actuator. A value of $\xi=4.5 \times 10^{-3}$ was found here for proper adjustment (using CoventorWare), as shown in Fig. 6(a). It was also observed [Fig. 6(a)] that the range of thermal conductivities given in the literature $(k=83-91 \mathrm{~W} / \mathrm{mK})$ does not produce differences in the $V-I$ curves, since the expected maximum temperature at the actuator is moderate: below $150{ }^{\circ} \mathrm{C}$ on contact, as shown in Fig. 7.

The measurement setup, which is shown in Fig. 6(b), was used for $V-I$ characterization. It is essential to deembed the bias accesses resistance (accesses are at constant room temperature) since this is comparable to the actuator resistance. In addition, note that the trench under the structure improves the actuator efficiency (there is negligible thermal coupling to substrate).

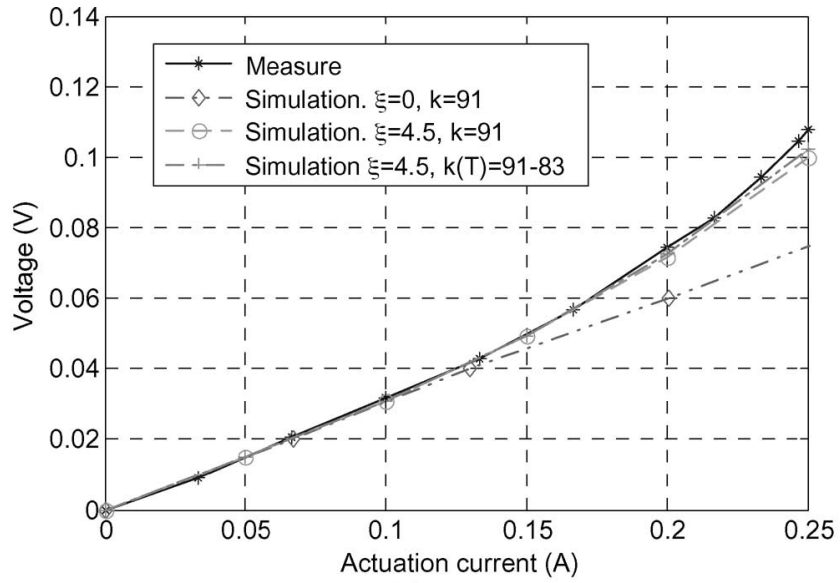

(a)

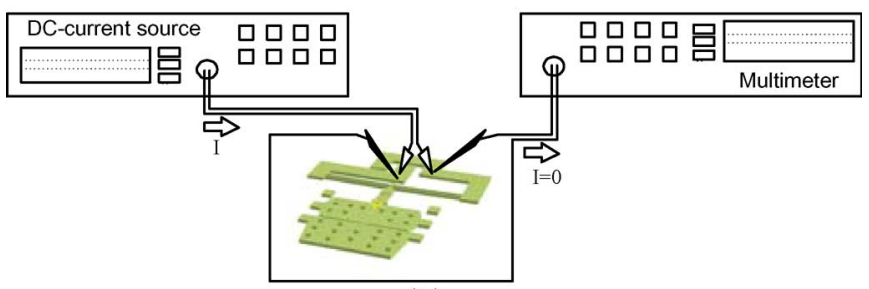

(b)

Fig. 6. (a) Electrical-resistivity adjustment for different situations (for one buckle beam) and (b) measurement setup.

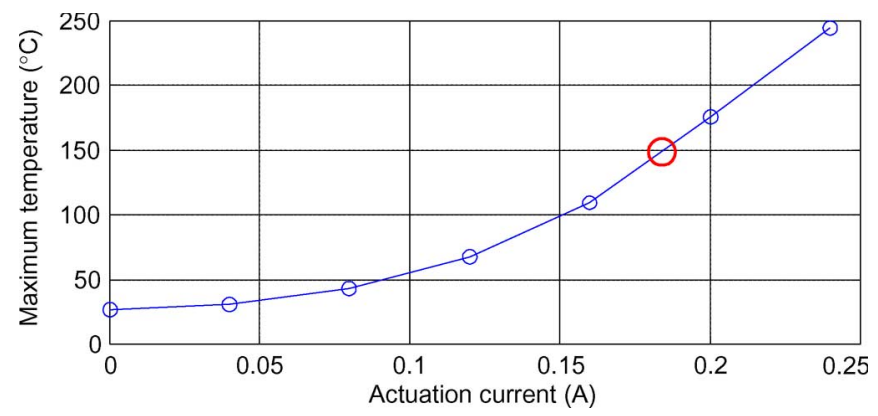

Fig. 7. Simulated maximum temperature at the actuator as a function of the applied current. The circle shows the point at which contact occurs.

Using the nickel properties obtained from Fig. 6 and assuming a value for the electroplated nickel thermal expansion coefficient $\alpha=12 \mathrm{ppm} / \mathrm{K}$ [20], the simulated displacement curve (using CoventorWare) is compared to the measured displacement in the manufactured device on contact in Fig. 8. A good agreement is observed.

Fig. 9 shows the contact and reaction forces versus the actuation current, normalized to contact current $\left(I_{\text {cont }}=370 \mathrm{~mA}\right)$. These results have been obtained by finite element analysis simulations (CoventorWare). A rapid increase in the contact force (simulated up to a maximum temperature at the actuator of $250{ }^{\circ} \mathrm{C}$ ) with current increase can be observed; values between $80 \mu \mathrm{N}$ and $3.5 \mathrm{mN}$ are obtained. Fig. 10 shows the reaction force before contact versus the displacement (normalized to the gap distance: $7 \mu \mathrm{m}$ ) which, as expected, shows a linear behavior.

These same analyses performed for other devices using different actuators validated the values found for the MetalMumps nickel properties, which are summarized in Table IV. 


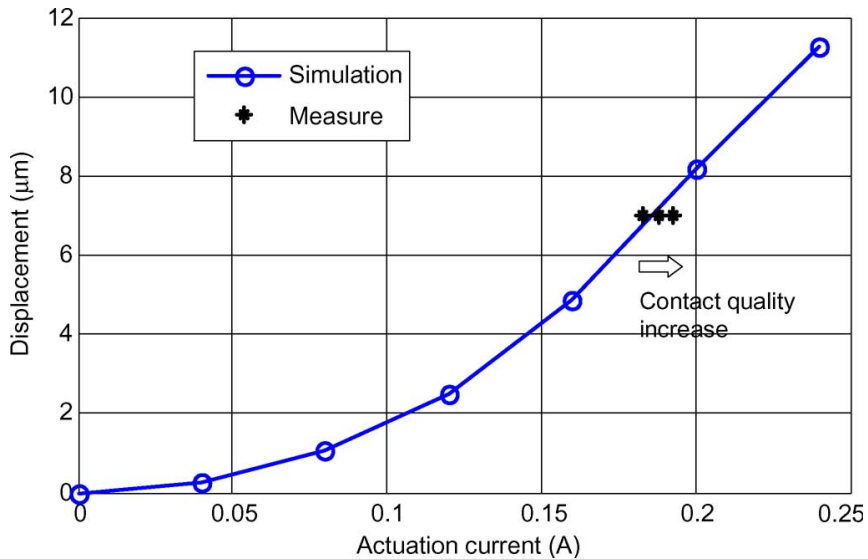

Fig. 8. Comparison between simulated and measured displacement on contact.

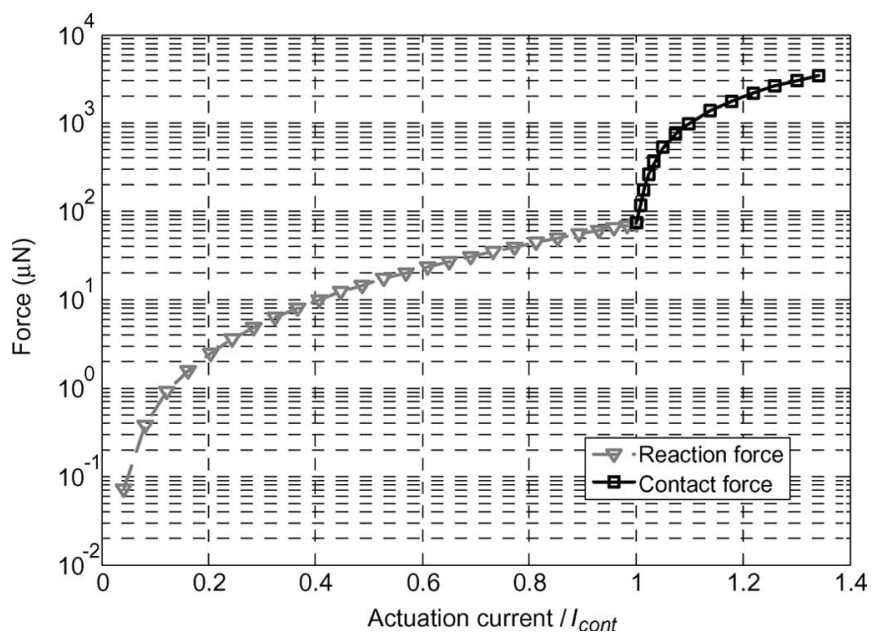

Fig. 9. Simulated contact and reaction forces versus the actuation current (normalized to contact current $I_{\text {cont }}=370 \mathrm{~mA}$ ).

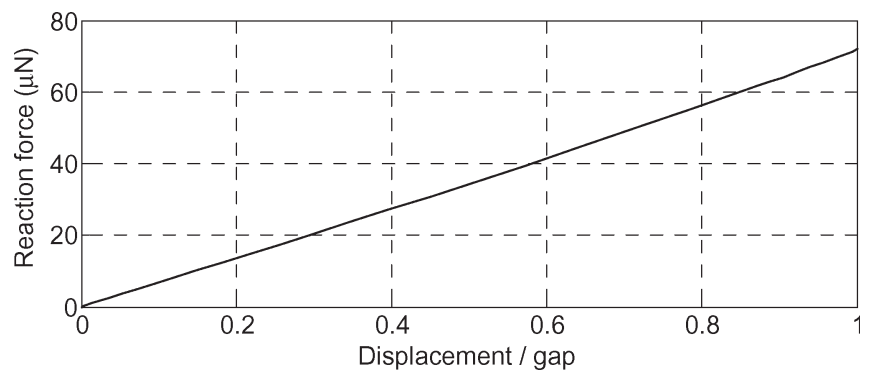

Fig. 10. Simulated reaction force versus displacement (normalized to the gap distance: $7 \mu \mathrm{m})$.

TABLE IV

Nickel Properties ObTained From Measurements

\begin{tabular}{lcc}
\hline \hline Resistivity $\left(T=0^{\circ} \mathrm{C}\right)$ & $\rho_{0}$ & $7.133 \times 10^{-8} \Omega . m$ \\
Temperature coefficient of resistivity & $\xi$ & $4.5 \times 10^{-3}$ \\
Thermal conductivity & $k$ & $91 \mathrm{~W} / \mathrm{mK} @ 273 \mathrm{~K}$ \\
& & $83 \mathrm{~W} / \mathrm{mK} @ 373 \mathrm{3}$ \\
Thermal expansion coefficient & $\alpha$ & $12 \mathrm{ppm} / \mathrm{K}$ \\
\hline \hline
\end{tabular}

From the previously mentioned results, it is clear that future improvements in actuation can be achieved. Obviously, the most important area of interest is current consumption.

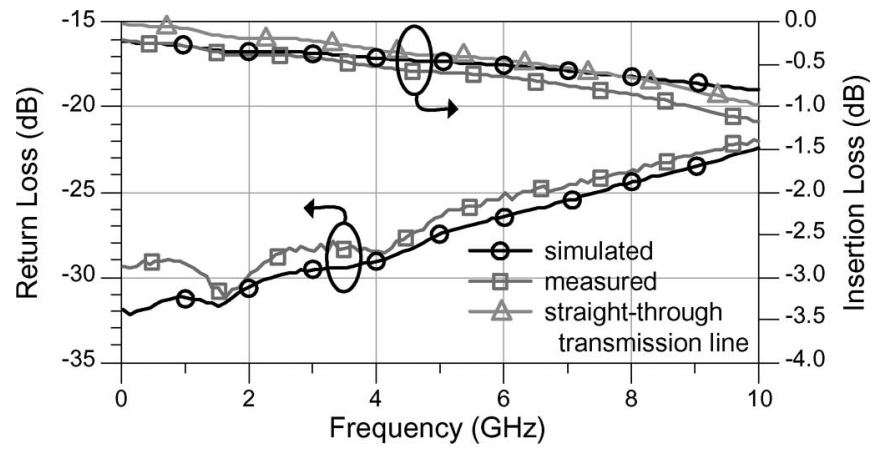

(a)

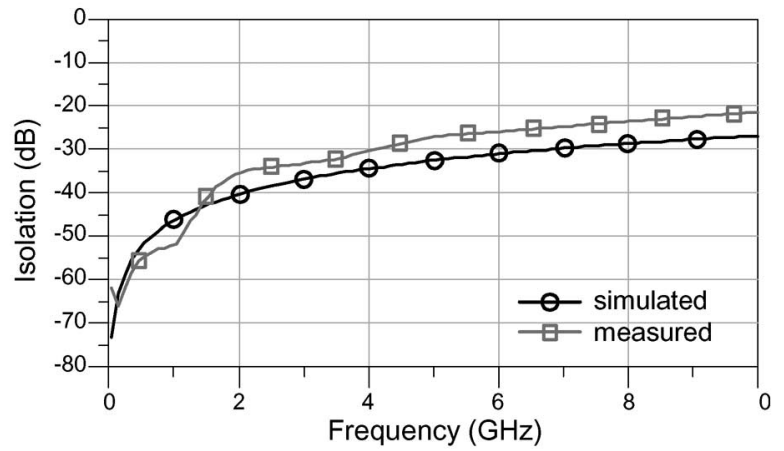

(b)

Fig. 11. Switch measured and simulated $S$-parameters compared to those of a straight through transmission line. (a) Insertion and return losses. (b) Isolation.

It was known from the beginning of this paper that current consumption cannot be further reduced in the present design due to the process restrictions on the actuator dimensions. Of course, once the actuator potential has been demonstrated, consumption could dramatically be decreased by making the actuator section smaller in future designs (not possible in the present MetalMumps process). It is estimated, however, that using MetalMumps, a further current reduction in future designs (up to $70 \%$ ) can also be achieved by using only one buckle beam; since sufficient force would remain, no coupling penalty in the array would exist, and actuator dimensions could then be optimized for these conditions.

\section{B. S-Parameter Measurement}

Fig. 11 shows the measured $S$-parameters of the switch compared to the results obtained from a 2.5-D ADS-Momentum electromagnetic simulation. On-wafer measurements were performed on a Cascade Microtech Summit 9000 probe station, using the "Line-Reflect-Reflect-Match" calibration technique [33] with the calibration plane at the probe tip; then, $S$-parameter measurements include the effect of the access pads. The simulation strategy is shown in Fig. 12. Since the measured pad $S$-parameters were known (see Section II-B), they could be used as part of the simulation. As a result, Momentum simulations concentrate on the suspended structure. The simulated suspended structure and the measured pads are recombined in a single ADS schematic to perform the final simulation. The measured RF results (insertion losses: $-0.26 \mathrm{~dB}$ at $1 \mathrm{GHz}$ and $-0.65 \mathrm{~dB}$ at $6 \mathrm{GHz}$; return losses: $-29 \mathrm{~dB}$ at 


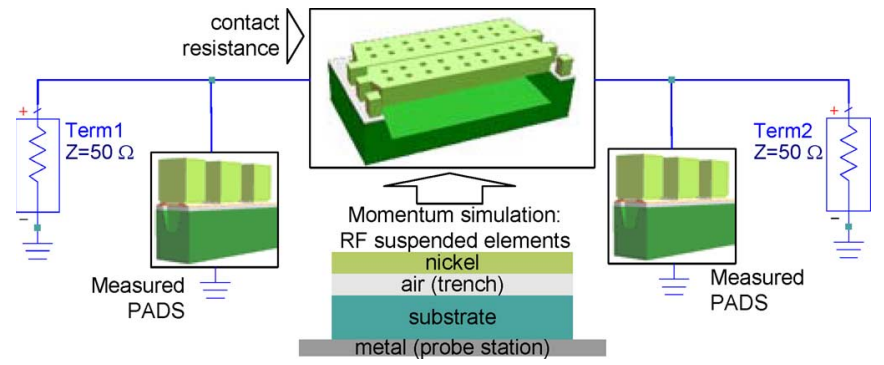

Fig. 12. Schematic of the simulation plan for MetalMumps devices with ADS-Momentum.

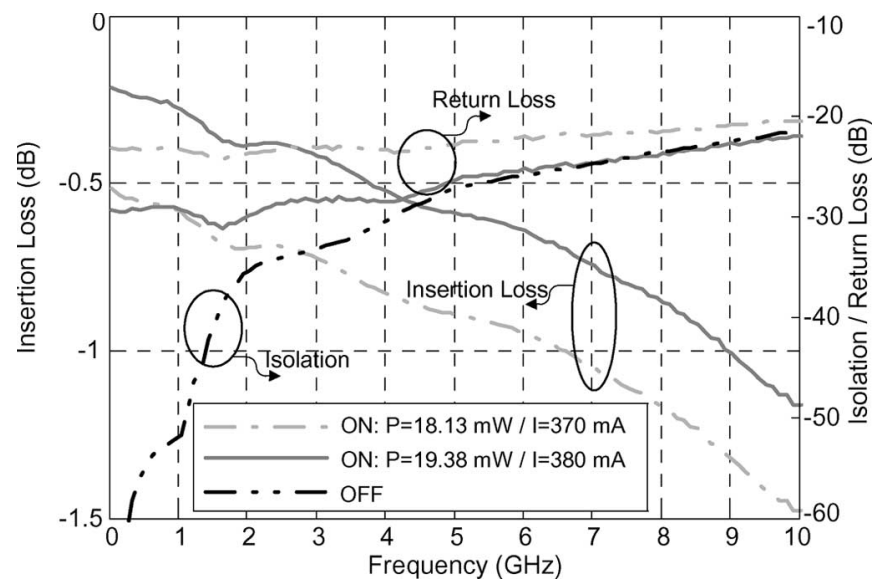

Fig. 13. Measured insertion loss, return loss, and isolation for two applied actuation powers.

$1 \mathrm{GHz}$ and $-25 \mathrm{~dB}$ at $6 \mathrm{GHz}$; isolations: $-52 \mathrm{~dB}$ at $1 \mathrm{GHz}$ and $-26 \mathrm{~dB}$ at $6 \mathrm{GHz}$ ) validate the strategy of suspending the structures on a low-resistivity substrate to obtain compact highperformance RF switches in low-gigahertz bands.

Fig. 11(a) also shows the measured insertion loss of a $50-\Omega$ straight through CPS transmission line (see dimensions in Fig. 5), which permits determination of the impact of the switch structure on loss. This line shows an attenuation of $2.91 \mathrm{~dB} / \mathrm{cm}$ at $2 \mathrm{GHz}$, which can be compared to the results shown in [34], where CPW lines manufactured on CMOS substrate are characterized; the study in [34] obtains attenuations (at $2 \mathrm{GHz}$ ) of $1.8 \mathrm{~dB} / \mathrm{cm}$ (when an air trench is carved under the lines in a postprocessing micromachining) and $6.5 \mathrm{~dB} / \mathrm{cm}$ (before carving the trench).

The dependence of the insertion loss and the contact resistance on the contact force is shown in Figs. 13 and 14. A relationship between the increased contact force and the decreased contact resistance has already been demonstrated in [10] and [26]. Fig. 13 shows the measured insertion and return losses for the two total actuation currents $I$ (or power $P$ ), which set the limits of initial/weak contact (for a total actuation current of $370 \mathrm{~mA}$, with high insertion loss) and consolidated contact (for a total actuation current of $380 \mathrm{~mA}$ ). The measured transition between these two states is shown in Fig. 14. It can be observed that the contact resistance decreases down to a value of $1.22 \Omega$ for a contact force of $320 \mu \mathrm{N}$ (see Fig. 9); this contact resistance can be considered constant in frequency [26] and is the one used in the simulations shown in Fig. 11. Increasing

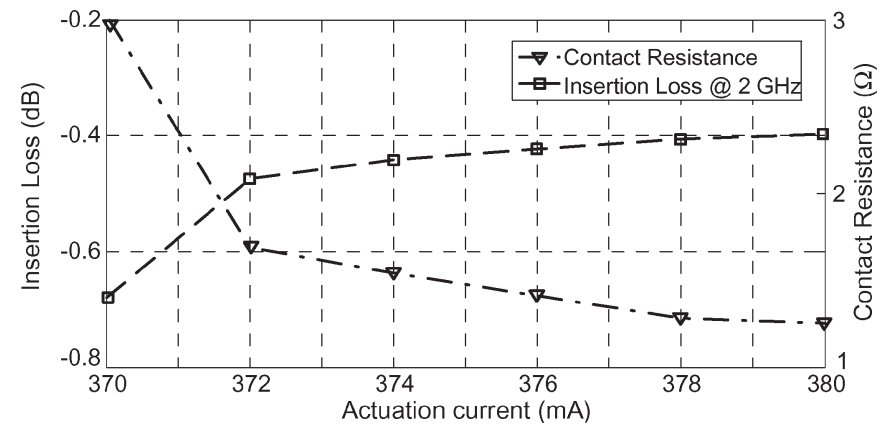

Fig. 14. Dependence of insertion loss (at $2 \mathrm{GHz}$ ) and contact resistance on the actuation current.

the actuation current (i.e., increase the contact force) does not decrease the contact resistance anymore, since the lower limit is not determined by force but by the material properties.

\section{RF POWER HANDLING}

The effect of the RF power on the switch performance is demonstrated by using two different approaches-hot and cold switching (actuation with and without RF power, respectively) — which are widely accepted as reliable methods for the characterization of the RF power handling in electrostatically actuated RF MEMS.

In electrostatically actuated shunt capacitive switches, the limitation on RF power handling comes mainly from the mechanisms of self-switching (in the case of cold switching) and RF latching (in the case of hot switching) [12]-[16]. So far, several topologies and solutions have been proposed in literature to improve the RF power handling [12], [13], [35].

In contrast, in the designed electrothermally actuated dccontact switch, it is expected that this limitation will be in the contact itself. The design topology provides independence between actuation and RF power; therefore, neither self-switching (a negligible electrostatic force appears between the moving and fixed contact parts due to RF voltage) nor RF latching (the mechanical restoring force is very large) is expected. As a result, the only potential limitation comes from the RF current and contact degradation, which can debase the contact quality (see Section II-C) identically to other resistive-contact switches.

To our knowledge, several dc-contact switches have been reported in literature to date, which are tested under highRF power conditions (cold switching in all cases): the Cronos switch $(6000 \mathrm{~mW}$ at $50 \mathrm{MHz}, 53$ million cycles) [28], the Rockwell switch ( $30 \mathrm{~mW}$ at $35 \mathrm{GHz}, 20-100$ million cycles) [28], and Radant MEMS has presented results of its switches [36], which are tested with $100 \mathrm{~mW}$, showing lifetimes greater than 100 billion cycles, and tested with $2 \mathrm{~W}$ and an active lifetime of 10 billion cycles. In addition, dc-power handling of microcontacts manufactured with MetalMumps (with an extra liquid-metal coating on the contacts) is reported in [25]. This paper reports as much as $120-\mathrm{V}$ and 0.5 -A hot switching across a $250-\Omega$ resistor and up to $50 \mathrm{~V}$ and $1 \mathrm{~A}$ across a $50-\Omega$ resistor. However, it also reports that contacts quickly deteriorate at such high power, and that one relay was used under hot-switching 


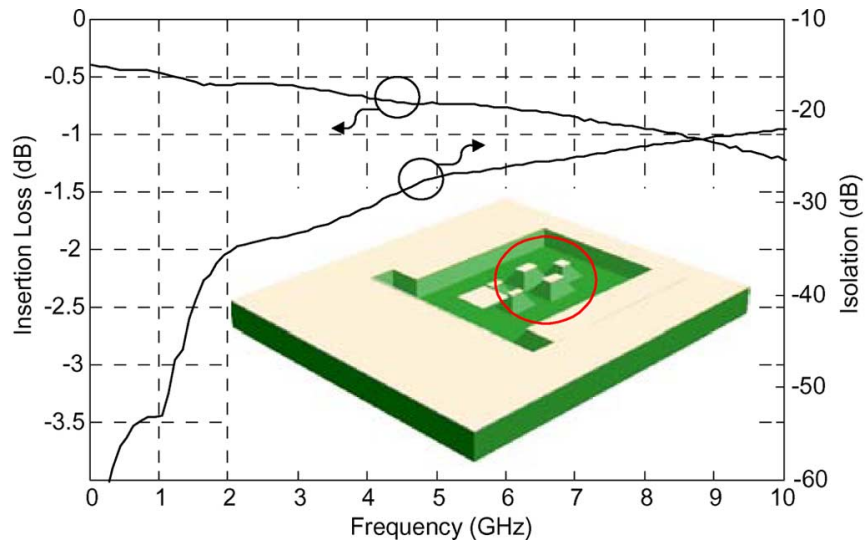

Fig. 15. Measured insertion loss and isolation of the switch for which RF power handling has been characterized. Small plot: additional mechanical supports (see inside the circle).
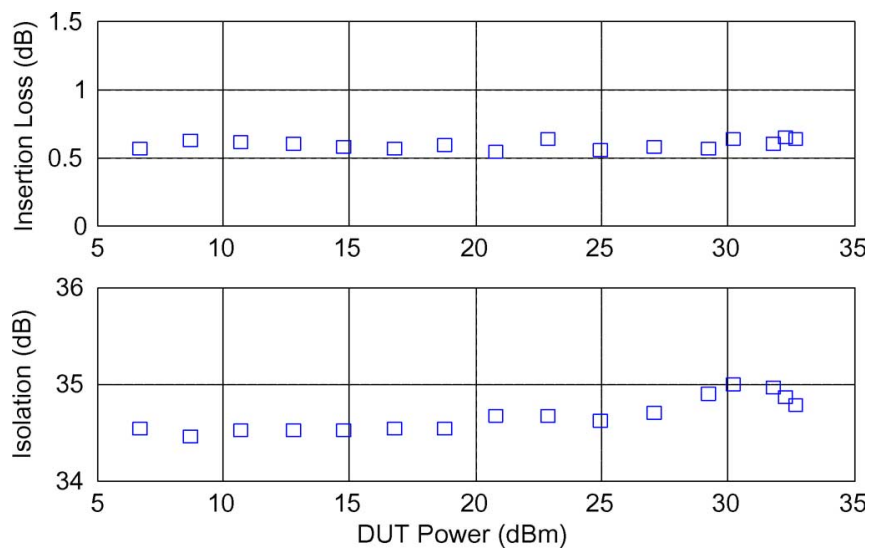

Fig. 16. RF power handling characterization under hot-switching conditions: the actuator current is turned on/off with the continuous presence of RF power in the device.

conditions at $10 \mathrm{~V}$ and $200 \mathrm{~mA}$ for over 1000 cycles before failure. Finally, $4 \mathrm{~A}$ and $200 \mathrm{~V}$ are recorded without contact welding using cold switching.

The $S$-parameters of the switch that has been characterized in this section are shown in Fig. 15. In contrast to the former switch, the one measured in this section integrates additional mechanical supports which make it more robust but has slightly increased capacitive coupling to substrate and losses. These mechanical supports are shown inside a circle in the inset of Fig. 15, where the device structure is hidden in order to show the trench in the substrate.

A measurement setup based on the systems proposed for RF power handling measurement in electrostatically actuated switches [13], [16] was used to characterize the effects of the RF power on the devices. Fig. 16 shows the measured results for hot switching and Fig. 17 for cold switching at $2 \mathrm{GHz}$ with up to $2 \mathrm{~W}$ of source available power. From these measurements, no significant variations or problems in the contacts, due to the RF power, can be observed. However, when the power is high and after a number of contacts, the RF lines show a slight movement: the lines are dragged by the contact when the contact separates. Since this movement occurs only with powers greater than $1.5 \mathrm{~W}$, it suggests that a high adherence
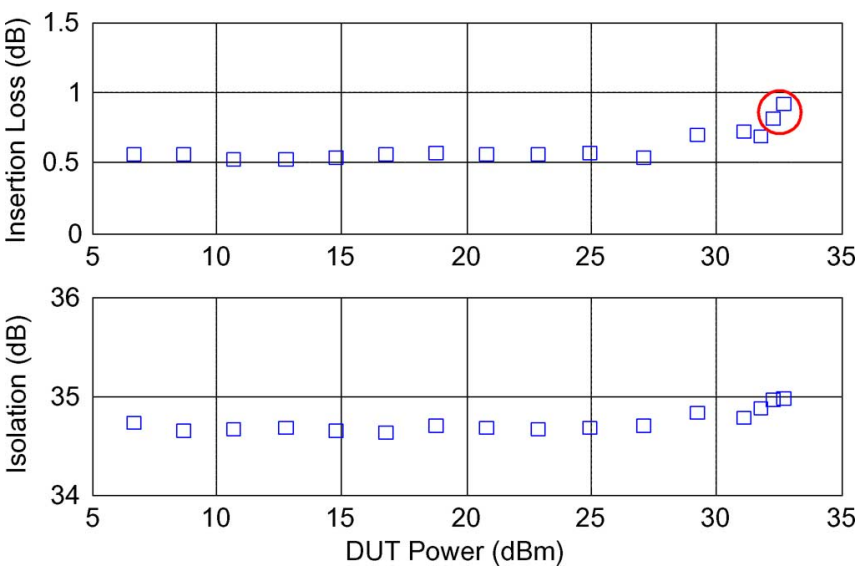

Fig. 17. RF power handling characterization under cold-switching conditions: the actuator current is turned on/off in the absence of RF power in the device. The circle indicates the variations in the insertion loss due to the movement of the RF lines.

force is experienced in the contacts due to temperature rise. Consequently, the contact is probably in its plastic region (moderated-temperature contact [26]). This problem results to variations in the insertion loss, as highlighted with a circle in Fig. 17. Improvements to this would be based on using a technology that could reduce surface roughness to increase the actual contact area by changing the gold manufacturing method (currently electroplating) or on applying a postprocessing metal coating on the contacts [25].

Finally, the switch showed a very good linear behavior, since no intermodulation distortion was observed in the twotone test, in either the ON or the OFF state, as expected from the topology. This test was carried out under the following conditions: frequency difference between tones, $100 \mathrm{~Hz}$; RF tone power, $30 \mathrm{dBm}$ each; RF frequency, $2 \mathrm{GHz}$.

\section{CONCLUSION}

An electrothermally actuated lateral resistive-contact series RF MEMS switch that is manufactured on a low-resistivity substrate has been presented. It is demonstrated that a good RF performance can be obtained by suspending the device $25 \mu \mathrm{m}$ above the substrate. Measured insertion losses were $-0.26 \mathrm{~dB}$ at $1 \mathrm{GHz}$ and $-0.65 \mathrm{~dB}$ at $6 \mathrm{GHz}$; return losses were $-29 \mathrm{~dB}$ at $1 \mathrm{GHz}$ and $-25 \mathrm{~dB}$ at $6 \mathrm{GHz}$; isolations were $-52 \mathrm{~dB}$ at $1 \mathrm{GHz}$ and $-26 \mathrm{~dB}$ at $6 \mathrm{GHz}$. This technique would potentially allow the switch to be integrated with active circuitry manufactured on a low-resistivity substrate in a system-on-chip concept, while maintaining good RF performance. Electrothermal actuation was used as the driving principle as it provides high forces, which are an important feature of resistive contacts. The actuator was implemented using nickel. It is demonstrated that nickel achieves greater displacements at much lower temperatures than polysilicon, which is an important issue when applied to packaged devices. The implemented topology features complete independence between actuation and RF signal. The RF power handling is limited by the resistive contact itself. This behavior was characterized at up to $2 \mathrm{~W}$ with both hot- and cold-switching approaches. 


\section{REFERENCES}

[1] H. A. C. Tilmans, W. de Raedt, and E. Beyne, "MEMS for wireless communications: 'From RF-MEMS components to RF-MEMS-SiP'," J. Micromech. Microeng., vol. 13, no. 4, pp. 139-163, Jul. 2003.

[2] D. Girbau, N. Otegi, L. Pradell, and A. Lázaro, "Study of intermodulation in RF MEMS variable capacitors," IEEE Trans. Microw. Theory Tech., vol. 54, no. 3, pp. 1120-1130, Mar. 2006.

[3] J. B. Muldavin and G. M. Rebeiz, "High-isolation CPW MEMS shunt switches-Part 1: Modeling," IEEE Trans. Microw. Theory Tech., vol. 48, no. 6, pp. 1045-1052, Jun. 2000.

[4] J. B. Muldavin and G. M. Rebeiz, "High-isolation inductively-tuned X-band MEMS shunt switches," in Proc. IEEE MTT-S Int. Microw. Symp., Jun. 2000, vol. 1, pp. 169-172.

[5] D. Mercier, P. L. Charvet, P. Berruyer et al., "A DC to $100 \mathrm{GHz}$ high performance ohmic shunt switch," in IEEE MTT-S Int. Microw. Symp. Tech. Dig., Jun. 2004, vol. 3, pp. 1931-1934.

[6] Y. Wang, Z. Li, D. T. McCormick, and N. C. Tien, "A low-voltage lateral MEMS switch with high RF performance," J. Microelectromech. Syst., vol. 13, no. 6, pp. 902-911, Dec. 2004.

[7] A. Q. Liu, M. Tang, A. Agarwal, and A. Alphones, "Low-loss lateral micromachined switches for high-frequency applications," J. Micromech. Microeng., vol. 15, no. 1, pp. 157-167, Jan. 2005.

[8] D. Girbau, L. Pradell, A. Lázaro, and A. Nebot, "In-plane electrostatically-actuated RF MEMS switch suspended on a lowresistivity substrate," in Proc. 36th Eur. Microw. Conf., Sep. 2006, pp. 1731-1734.

[9] L. Que, J. S. Park, and Y. B. Gianchandani, "Bent-beam electro-thermal actuators for high-force applications," in Proc. IEEE Int. Conf. MEMS, Jan. 1999, pp. 31-36.

[10] E. J. J. Kruglick and K. S. J. Pister, "Lateral MEMS microcontact considerations," J. Microelectromech. Syst., vol. 8, no. 3, pp. 264-271, Sep. 1999.

[11] D. Girbau, A. Lázaro, and L. Pradell, "RF MEMS switches based on the buckle-beam thermal actuator," in Proc. 33rd Eur. Microw. Conf., Oct. 2003, vol. II, pp. 651-654.

[12] B. Ducarouge, E. Perret, F. Flourens, H. Aubert, J. W. Tao, X. Chauffleur, J. P. Fradin, D. Dubuc, K. Grenier, P. Pons, and R. Plana, "Design of MEMS-based microwave and millimeterwave switches for high power measurements," in Proc. Int. Semicond. Conf., Sep. 2003, vol. 1, pp. 61-64.

[13] D. Peroulis, S. P. Pacheco, and L. P. B. Katehi, "RF MEMS switches with enhanced power-handling capabilities," IEEE Trans. Microw. Theory Tech., vol. 52, no. 1, pp. 59-68, Jan. 2004.

[14] J. R. Reid, L. A. Starman, and R. T. Webster, "RF actuation of capacitive MEMS switches," in IEEE MTT-S Int. Microw. Symp. Tech. Dig., Jun. 2003, vol. 3, pp. 1919-1922.

[15] J. Muldavin, R. Boisvert, C. Bozler, S. Rabe, and C. Keast, "Power handling and linearity of MEM capacitive series switches," in IEEE MTT-S Int. Microw. Symp. Tech. Dig., Jun. 2003, vol. 3, pp. 1915-1918.

[16] B. Pillans, J. Kleber, C. Goldsmith, and M. Eberly, "RF power handling of capacitive RF MEMS devices," in IEEE MTT-S Int. Microw. Symp. Tech. Dig., Jun. 2002, vol. 1, pp. 329-332.

[17] A. Cowen, B. Dudley, E. Hill et al., MetalMUMPs Design Handbook. Rev. 1.0. [Online]. Available: http://www.mwmsrus.com/ nc-mumps.metal.html

[18] M. Bakri-Kassem and R. Mansour, "Two movable-plate nitride-loaded MEMS variable capacitor," IEEE Trans. Microw. Theory Tech., vol. 52, no. 3, pp. 831-837, Mar. 2004.

[19] S. L. Firebaugh, "Packaging considerations for microelectromechanical microwave switches," in Proc. ECTC, Jun. 2004, pp. 862-868.

[20] L. Que, J. S. Park, and Y. B. Gianchandani, "Bent-beam electrothermal actuators-Part I: Single beam and cascaded devices," J. Microelectromech. Syst., vol. 10, no. 2, pp. 247-254, Jun. 2001.

[21] M. J. Sinclair, "A high-force low-area MEMS thermal actuator," in Proc. IEEE Inter Society Conf. Thermal Thermomechanical Phenomena Electron. Syst., May 2000, pp. 127-132.

[22] J. K. Luo, J. H. He, A. J. Flewitt, D. F. Moore, S. M. Spearing, and N. A. Fleck, "Development of all metal electro-thermal actuator and its applications," in Proc. SPIE-MEMS/MOEMS Components Their Applications, Jan. 2004, vol. 5344, pp. 201-210.

[23] H. S. Cho, K. J. Hemker, K. Lian, J. Goettert, and G. Dirras, "Measured mechanical properties of LIGA Ni structures," Sens. Actuators A, Phys., vol. 103, no. 1, pp. 59-63, Jan. 2003.

[24] W. N. Sharpe, D. A. LaVan, and R. Edwards, "Mechanical properties of LIGA-deposited nickel for MEMS transducers," in Proc. Int. Conf. SolidState Sens. Actuators, Transducers, Jun. 1997, pp. 607-610.
[25] A. Cao, P. Yuen, and L. Lin, "Bi-directional micro relays with liquidmetal wetted contacts," in Proc. 18th IEEE Int. Conf. MEMS, Feb. 2005, pp. 371-374.

[26] B. D. Jensen, L. W. Chow, R. F. Webbink, K. Saitou, and J. L. Volakis, "Force dependence of RF MEMS switch contact heating," in Proc. IEEE Int. Conf. Micro Electro Mech. Syst., 2004, pp. 137-140.

[27] D. Hyman and M. Mehregany, "Contact physics of gold microcontacts for MEMS switches," IEEE Trans. Compon. Packag. Technol., vol. 22, no. 3 , pp. 357-364, Sep. 1999.

[28] G. M. Rebeiz, RF MEMS, Theory, Design, and Technology. Hoboken, NJ: Wiley, 2003.

[29] S. Majumder, N. E. McGruer, G. G. Adams, P. M. Zavracky, R. H. Morrison, and J. Krim, "Study of contacts in an electrostatically actuated microswitch," Sens. Actuators A, Phys., vol. 93, no. 1, pp. 19-26, Aug. 2001.

[30] S. S. Gevorgian and I. G. Mironenko, "Asymmetric coplanar-strip transmission lines for MMIC and integrated optic applications," Electron. Lett., vol. 26, no. 22, pp. 1916-1918, Oct. 1990

[31] S. S. Bedair, "Characteristics of some asymmetrical coupled transmission lines," IEEE Trans. Microw. Theory Tech., vol. 32, no. 1, pp. 108-110, Jan. 1984.

[32] J. B. Knorr and K. D. Kuchler, "Analysis of coupled slots and coplanar strips on dielectric substrate," IEEE Trans. Microw. Theory Tech., vol. MTT-23, no. 7, pp. 541-548, Jul. 1975.

[33] F. Purroy and L. Pradell, "New theoretical analysis of the LRRM calibration technique for vector network analyzers," IEEE Trans. Instrum. Meas., vol. 50, no. 5, pp. 1307-1314, Oct. 2001.

[34] V. Milanovic, M. Gaitan, E. D. Bowen, and M. E. Zaghloul, "Micromachined microwave transmission lines in CMOS technology," IEEE Trans. Microw. Theory Tech., vol. 45, no. 5, pp. 630-635, May 1997.

[35] K. M. Strohm, B. Schauwecker, D. Pilz, W. Simon, and J.-F. Luy, "RF-MEMS switching concepts for high power applications," in Proc. Top. Meeting Silicon Monolithic Integr. Circuits RF Syst., Sep. 2001, pp. 42-46.

[36] H. J. De Los Santos, S. Rassoulian, and J. Maciel, "MEMS for future microwave systems," in IEEE MTT-S Int. Microw. Symp. Tech. Dig., Jun. 2005, pp. 905-908.

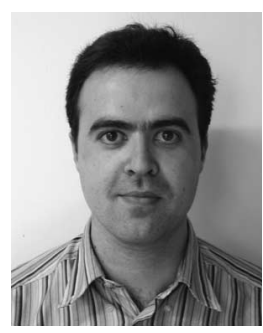

David Girbau received the Technical Telecommunication Engineering degree, the Electronics Engineering degree, and the Ph.D. degree in telecommunications from the Universitat Politècnica de Catalunya (UPC), Barcelona, Spain, in 1998, 2002, and 2006, respectively.

Since February 2001, he has been a Research Assistant with the Department of Signal Theory and Communications, UPC. Since September 2005, he has also been a Part-Time Assistant Professor with the Universitat Autònoma de Barcelona, Barcelona. His primary research interests include RF and microwave devices and systems, with emphasis on RF-MEMS.

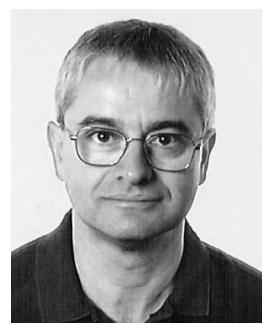

Lluís Pradell (M'87) was born in Barcelona, Spain, in 1956. He received the Telecommunication Engineering degree and the Dr. degree in telecommunication engineering from the Universitat Politècnica de Catalunya (UPC), Barcelona, Spain, in 1981 and 1989 , respectively.

From 1981 to 1985 , he was with the company Mier-Allende, Barcelona, as an RF and Microwave System Design Engineer. In 1985, he joined the faculty at UPC, where he became an Associate Professor in 1990. Since 1985, he has been teaching courses on microwave circuits and antennas, and performing research on models for microwave active devices (MESFET, HEMT, HBT), multimodal models for guiding structures and transitions (microstrip, finline, slotline, and coplanar waveguide), on-wafer measurement techniques (network-analyzer calibration, noise parameters), development of microwave and millimeter-wave systems (low-noise amplifiers and point-to-multipoint broadband communication systems), and RF and microwave microelectromechanical systems, in the frequency range $1-75 \mathrm{GHz}$. 


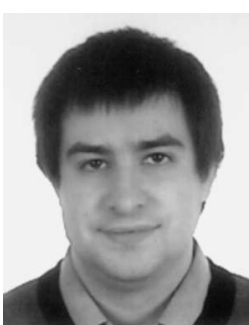

Antonio Lázaro was born in Lleida, Spain, in 1971. He received the M.S. and Ph.D. degrees in telecommunication engineering from the Universitat Politècnica de Catalunya (UPC), Barcelona, Spain, in 1994 and 1998, respectively.

He was a member of the faculty at UPC, where he taught a course on microwave circuits and antennas. He is currently with the Electronics, Electrical, and Automatics Engineering Department, University Rovira i Virgili, Tarragona, Spain. His research interests are microwave device modeling, on-wafer noise measurements, monolithic microwave integrated circuits, low-phase noise oscillators, microelectromechanical systems, and microwave systems.

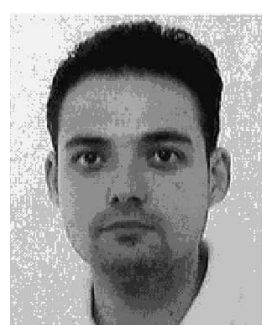

Àlvar Nebot received the Technical Telecommunication Engineering degree from the Universitat de Vic, Vic (Barcelona), Spain, in 2001, and the Electronics Engineering degree from the Universitat Politècnica de Catalunya, Barcelona, in 2006.

$\mathrm{He}$ is with the Department of Signal Theory and Communications, Universitat Politècnica de Catalunya. 